\title{
POR UMA HERMENÊUTICA DO DESIGN: A PERFORMANCE COMO CONCEITO ANALÍTICO
}

Valquíria Guimarães Duarte

Universidade Federal de Goiás

Valgd44@hotmail.com

Resumo: Este artigo propõe apresentar a continuidade da pesquisa iniciada em 2012, e tem como objetivo apresentar conceitos operadores e analíticos para uma hermenêutica e crítica do design. Partindo dos estudos da História e Teoria Interartes (dos operadores Fusão, Diferenciação e Intervalo), apresentamos conceitos analíticos de natureza transdisciplinar, nascidos da interlocução com a Teoria da Arte, a Filosofia e a Teoria da História. Sabendo que a produção contemporânea apresenta linguagens que não se reduzem aos temas da separação e autonomização das linguagens, mas envolvem estéticas e elementos do classicismo, do barroco e do romantismo, reconfigurados nas formas do debate contemporâneo acerca da modernidade e da pós-modernidade, voltamo-nos para a problematização dessas questões: neste artigo, especificamente, nos detemos nos conceitos analíticos da Performance.

Palavras-chave: Teoria e crítica do Design; Estudos Interartísticos; Conceitos operadores e analíticos; Performance.

Abstract: This article proposes to present the continuation of the research started in 2012 and aims to present operators and analytical concepts to a hermeneutic and critical design. We left the studies of History and Theory Interartes (operators Fusion, Differentiation and Interval), and present analytical concepts of transdisciplinary nature, born of dialogue with the theory of art, philosophy and theory of history. Knowing that contemporary production has languages that are not reducible to the themes of separation and autonomy of languages, but involve aesthetic and elements of Classicism, Baroque and Romanticism, reconfigured in the forms of the contemporary debate about modernity and postmodernity, we turn to problematize these issues: we present, now, the Performance concepts.

Keywords: Design Theory and Critic; Interartistic Studies; Analytical and Operators Concepts; Performance. 


\section{INTRODUÇÃO}

A poética do design contemporâneo não se reduz aos temas da separação das linguagens, mas seu hibridismo e profusão de meios envolvem estéticas ligadas ao clássico, barroco e romântico, reconfigurados nas formas do debate contemporâneo acerca da modernidade e da pós-modernidade. Essa complexidade, contaminada por diversas disciplinas (arte contemporânea, teatro, cinema, arquitetura), exige um sistema teórico para sua compreensão (que não só o da autonomização das linguagens), que abranja todas as estéticas envolvidas na criação do objeto (processo) ou do ambiente. A produção contemporânea também apresenta variadas posturas filosóficas, mecanismos criativos e lógicas espaciais, além de se constituir em fenômenos que incluem uma diversidade de meios e tecnologias.

Uma questão relevante aos estudos interartísticos diz respeito à escolha dos moldes de tratamento das diferentes linguagens e suas interfaces - as formas artísticas, as relações estruturais, as abordagens de cunho semântico (e os problemas do conteúdo), os recursos à expressividade e as relações no campo sígnico. Tradicionalmente, e na perspectiva dos estudos da História e Teoria Interartes, a problemática se relaciona ao fazer artístico (à poética) na contextura renascentista, na retomada do debate do Ut Pictura Poesis. Neste sentido, as questões problematizadas estão entre os aspectos técnicos (poéticos) e de retórica. No século $X X$, a discussão passa para o campo das correspondências (Estética Comparada) e para as diferentes abordagens formais-estruturais das linguagens (Souriau, Praz, Lévi-Strauss, estruturalismos, semióticas) (Noronha, 2008, p.1).

No domínio do que a Teoria Interartes apresenta como ferramenta de pesquisa, três conceitos operadores dão abertura para a elaboração de conceitos analíticos que proporcionem meios para uma história, teoria e crítica interartística (Noronha, 2008, p.2). Esses conceitos, Fusão, Diferenciação e Intervalo ${ }^{1}$, permitem o desenvolvimento de raciocínios em torno do objeto, em torno do método, e um raciocínio em torno dos trânsitos temporais-espaciais, arregimentados pela escrituravisualidade-performance, na produção de "Scinestesias" (Noronha), sendo algo que está entre, no intervalo, além dos corpus já constituídos. O raciocínio aqui é o de entender a situação "encenada" pela obra/processo como geradora de uma estrutura num espaço descontínuo e num tempo múltiplo, promovendo, na simultaneidade, diversos níveis de realidade.

Esses três conceitos operadores guardam interlocuções com outros três aspectos relevantes para uma hermenêutica interartística: a Scinestesia, Audio-Visual e

${ }^{1}$ Os estudos interartísticos têm como projeto desenvolver conceitos que relacionem obras (processos criativos, semioses, paradigmas), e contextos/ historicidades (tradições, sintagmas, dentro de hermenêuticas filosóficas e culturais), em uma pesquisa que busque o potencial do fenômeno como gerador de sentidos, criando uma estrutura em um espaço contínuo e num tempo múltiplo, promovendo, na simultaneidade, diversos níveis de realidade A proposta abrange três categorias operacionais estratégicas, que observam três lógicas: Fusão, Diferença e Intervalo. Esses conceitos permitem o desenvolvimento de raciocínios de análise em torno do objeto (que é atravessado por múltiplos olhares disciplinares), em torno do método (já que se transferem reflexões teóricas de um lugar a outro na geração de produtos e conceitos intermediários), e um raciocínio em torno dos trânsitos temporais-espaciais, agenciados pela escritura, visualidade e performance, na produção de Scinestesias, obtendo um resultado de análise que está no entre, além do corpus teórico constituído. Deste modo o fenômeno estudado se coloca no Intervalo, num deslocamento de fronteira. 
Performance ${ }^{2}$. Esses "apoios" conceituais dão suporte à investigação e a criação e a análise em torno do objeto de pesquisa. Neste artigo, especificamente, nos deteremos a uma operação transdisciplinar entre arte e design - elaborada a partir da teoria da Performance.

Atualmente, muito do que se produz de design se apoia em estratégias de raciocínio topológico ${ }^{3}$ e das semioses interartísticas, sugerindo a práxis e sua compreensão a partir do deslocamento de fronteiras disciplinares (demonstrando um interesse em ultrapassá-las). Esse é um aspecto importante a ressaltar: se consideramos as fronteiras disciplinares - seus princípios norteadores -, e por outro lado, consideramos a contaminação conceitual, processual e estrutural, conseguimos uma operação transdisciplinar. Os conceitos de Performance surgem a partir do exercício de comparações entre os dois campos de conhecimentos.

\section{ARTES DE FRONTEIRA}

FRONTEIRA ARTE X DESIGN - Em seu artigo "A escultura no campo ampliado das artes", Rosalind Krauss (1996) retoma a discussão em torno da autonomia dos meios artísticos, observando mudanças ocorridas na produção da escultura do período. A autora reivindica uma redefinição do conceito de escultura, afirmando que há uma intrínseca ligação entre escultura, arquitetura e paisagem, visto que a produção artística contemporânea possibilita a concretização de uma arte mais ligada a intervenções de lugares. Há também uma mudança na relação de fruição, que passa da tridimensionalidade para quadridimensionalidade prospectiva, para uma situação de estar entre, de atravessamento, em uma experiência scinestésica (Noronha) e participativa do espectador. Embora a criação artística guarde relações com o objeto, o espaço (o design) há mais tempo ${ }^{4}$, a partir dos anos 60 há um afrouxamento conceitual

\footnotetext{
${ }^{2}$ A Scinestesia (Noronha) aponta para uma conjunção entre Sinestesia e Cinestesia, e diz respeito à reintegração de duas condições no campo da pesquisa da linguagem: a primeira (sinestesia) é a relação de planos sensoriais diferentes, ou seja, a capacidade de tradução inter-percepções, num grau indicial (plano semiótico), estabelecendo relações entre uma percepção de um domínio do sentido e outro domínio evocado O Auvio-visual (desdobrado em termos, como, paradigma do filme, paradigma cinemático ou efeito-cinema, artes espacio-visuais).se detém nas zonas de produção em arte, o vídeo e suas combinações em intervalos tais como, vídeo-arte, vídeo-dança, vídeo-performance - tem demonstrado ser uma mídia de grande capacidade de exploração, por ser uma zona entre-imagens e um modo de promover uma visualidade-visibilidade - de fazer ver algo da ordem do registro-, transformando-as em visualidades estáveis em torno do mundo contemporâneo São os novos encontros com o efeito de verdade ou, quem sabe, um desejo do Real. O registro como algo da ordem da poética integra-se à dimensão do pesquisador/designer enquanto etnógrafo, comum ao mundo contemporâneo.

${ }^{3}$ No raciocínio topológico, o que conta é a condição relacional, na articulação entre o corpo e o espaço. Esse raciocínio evidencia o modo como o espaço é utilizado ou apreendido pelo interagente. A ordem topológica é invisível na sua totalidade, mas inteligível pela percepção cinestésica e sinestésica percebida, visualizada e percorrida.

4 Podemos exemplificar a ampliação do conceito de escultura muito antes disso, com a criação da obra Merzbau (Casa Merz), de Kurt Schwitters (1923 a 1943), uma espécie de obra colagística em processo, montada no apartamento do artista. Embora esta seja considerada uma proto-instalação, O'Doerty (2007) comenta que, há uma relação de fruição que não a encaixa na categoria que muito anos depois vem a ser conhecida como instação, visto os espectadores ainda conservarem uma fruição aos moldes da arte bidimensional, explorando a visão e não a percepção corporal. Nos anos subsequentes à obra Merzbau, a arte ultrapassa as molduras do quadro, "descarta o plinto", não só ocupam o espaço mais
} 
de categorias, assim como um "desmantelamento" das fronteiras artísticas, que passam de uma autonomia de meios para uma pluralidade de linguagens. Krauss reacende reflexões sobre autonomia disciplinar propugnadas no tratado estético de Lessing (séc. XVIII), sugerindo que contemporaneamente a produção artística promove uma oportuna dissolução de fronteiras disciplinares. As práticas artísticas contemporâneas, que a partir de meados do século XX mudaram a face da produção escultórica, dificultam o uso dos mesmos termos em sua análise e compreensão. 0 universo abrangente de processos, materiais, mídias, implicam uma revisão do conceito. "O campo expandido da arte", como sugere as problematizações em torno da "escultura" contemporânea, revela uma ligação da arte com o espaço mais vasto: do design, da arquitetura e da paisagem.

As reflexões de Krauss sobre as transformações do conceito de escultura que acontecem no limiar da arte contemporânea (a escultura toma as práticas teóricas da arquitetura para transformar seu campo) nos levam a refletir sobre as mudanças ocorridas no campo do design e do design em relação à cidade. De modo similar, o design, manipulado como uma prática artística, transforma e rejeita termos tradicionais (como o funcionalismo e os códigos formais da abstração modernista). Se a arte por muito tempo serve de modelo para o design (e ainda segue servindo), também se pode dizer que o design pode ser problematizado como modelo para arte, e uma vez pensado enquanto instalação é um produto em interface que está associado às formas contemporâneas do hipertexto. Observando a produção da arquitetura do tempo recente, ressaltamos características que a conecta não só às Instalações artísticas, o In Situ ou Site Specific, à Land Art, a Arte Multimídia, assim como a continuidades das relações com as esculturas modernas. Também observamos, nos processos de criação em design, ligações com as categorias artísticas da Performance. Deste modo, instaura-se o diálogo aberto e abre-se caminho à discussão das práticas teóricas.

FRONTEIRA DESIGN X ARTE - Na produção do design contemporâneo há o interesse em buscar um campo ampliado (usando o termo de Krauss) como alternativa para superar os dualismos conceituais da forma $\mathrm{x}$ função, abstração $\mathrm{x}$ historicismo $\mathrm{e}$ utopia $x$ realidade, que estiveram no centro das discussões do campo durante todo 0 século XX. Os processos criativos encontram novas aspirações formais e programáticas em um vasto conjunto de disciplinas e tecnologias, que valorizam as multiplicidades e pluralidades. As fronteiras disciplinares entre arte e design estão cada vez mais contaminadas. Assim, a paisagem e a escultura - a não-paisagem e a não-escultura emergem como metáforas exemplares dentro de uma nova condição do design.

O design contemporâneo pode ser visto como paisagem e escultura - uma nãoexatamente-paisagem e uma não-exatamente-escultura -, e dentro desse raciocínio de ultrapassagem de fronteiras e hibridismo conceitural, pode ser problematizado como um "não-exatamente-design".

O campo expandido da arte de Krauss (1996) ajudam a refletir sobre o design contemporâneo de natureza híbrida. E esse conceito dialoga com o Intervalo, na medida em que discutem campos contaminados, quando sugerem a transmutação conceitural entre um campo e outro.

vasto da galeria como também da cidade, além de captar o instante, como nos Happenings, que segundo Archer (2001) sinalizam a ampliação dos gestos expressionistas para o espaço. 
Há uma lógica do Intervalo (de uma Fusão contemporânea) em que o princípio convocado é o da produção de uma forma-arte resultante da interlocução entre as categorias da arte. O conceito aponta para reflexões sobre um dos aspectos da "obra de arte total". A ideia da realização de uma síntese das artes contemporânea importa quanto se trata de pensar o design enquanto arte e a noção wagneriana de síntese, reconfigurada a partir do debate do design do tempo presente; ou seja, a partir de uma estética híbrida, fronteiriça e experimental, que se apresenta em uma profusão de meios ${ }^{5}$.

A ideia wagneriana de Obra de Arte Total (exemplificada pela ópera), com seus dispositivos, provoca a imersão completa do espectador, que abraça a completude da experiência sensório-corporal e estética. Nesse sentido, pode-se afirmar que a integração das diferentes artes de outrora é somada, no presente, às novas mídias, que incluem o universo digital.

\section{PERFORMANCE COMO CONCEITO ANALÍTICO.}

Ao considerar as contaminações, fronteiras e hibridismo da produção do design contemporâneo, convocamos o operador Intervalo ${ }^{6}$ para pensar em uma relação transdisciplinar entre Design e Performance Artística ${ }^{7}$, com o objetivo de criar conceitos para uma hermenêutica. A Performance se torna uma estratégia por excelência na apreensão de uma história entre imagem, texto, som e corpo, já que nasce em uma zona de entrelaçamento intertextual - em um ponto de encontro entre diferentes linguagens artísticas -, cujas formas de diálogo não convencionais incidem com maior ou menor força. Trata-se de analisar de que forma se dá, no Design, as relações entre Corpo, Objeto, Espaço e Performance. O estudo da Performance nos amplia a noção do termo, do campo da arte para a esfera do Design.

Para Glusberg (2009), a Performance tem como predecessores criativos o Dada (Collages, Assemblages e Environments), o Happening (que desenvolve a partir do

\footnotetext{
${ }^{5}$ Chamamos atenção para a retomada contemporânea do debate em torno do Ut Pictura Poiesis com o advento da hibridização da arte: na esteira do raciocínio proposto por Souriau (1983), o estudo da correspondência entre as artes corrobora a ideia de que "artes são todas as artes", o que traz uma compreensão mais abrangente e amplia o entendimento do fenômeno estético como um todo (Souriau, 1983, p.2). Desde a antiguidade clássica, dentro dessa perspectiva, reconhece-se que há uma convergência entre práticas artísticas em princípio tão díspares, como por exemplo, a pintura, a poesia, a escultura, a dança. Embora a teoria estética tenha se desenvolvido no sentido de definir os limites das artes plásticas (Lessing) - sujeitas às condições específicas de cada campo. O clássico debate é retomado no contexto renascentista - em que se discute a relação da técnica e poética com a retórica -, e ganha força nas teses do romantismo alemão, no séc. XIX, em que se desenvolve um programa teórico e de produção. Contemporaneamente o debate Ut Pictura Poiesis é retomado com o advento da hibridização da arte.

${ }^{6}$ Intervalo, como o termo já evidencia, é a lógica do inter, do entre, num vai-e-vém do aquém e do além ao através, demonstrando um interesse pela ultrapassagem, deslocamento de fronteiras, raciocínio topológico e das semioses interartísticas; o modo da instalação, com alto grau de aplicação de princípios construtivos às artes visuais; produtos em interface; efeitos de dispositivos de certos media em outros suportes de produção.

${ }^{7}$ Performance advém do inglês to perform, que por sua vez se origina do termo latino formare, que significa "dar forma a" ou performatus, "acabado de formar". A palavra pode designar, entre outras coisas, a aparência física ou desempenho do corpo, ou ainda um método a partir do qual se origina um corpo. Também aparecem como sinônimos, segundo Schechner (2006) "execução, desempenho, façanha, representação, quadro".
} 
Environment e Live art) e a Body Art (uso do corpo como base para reflexões da arte), em seus caracteres cênico-teatrais, que pontuam dinâmicas ritualísticas e extensões semiológicas que convergem e sintetizam uma efetuação performática Como categoria artística (criada nos anos 70), apresenta duas conotações: a de uma presença física, e a de um espetáculo, no sentido de algo para ser visto (Glusberg, 2009, p.43) Nesse sentido, pode-se relacioná-la a outras categorias artísticas, como o teatro, a dança e a música Noronha (2008-A) assinala, a partir Jean Lauxerois e Peter Szendy (IRCAM), que o paradigma fundacional da Performance é anterior a ela mesma e diz respeito a uma experiência constituída no cinema e na formação de um paradigma audiovisual Ou seja, a Performance pode ser observada dentro da estética do Intervalo porque se trata, desde o início, de uma relação interartística, problematizada a partir do cinema e seus dispositivos, que convocam as demais artes à reflexões sobre o modo de ver e perceber uma obra, "...dos Happenings (live events) às Instalações, o que é exposto é o próprio olhar - e a escuta - $e$ as condições da produção de uma sensibilidade audiovisual - uma sensibilidade ótico-sonora" (Noronha, 2008-A, p.11-12)

A Performance é um território de várias interfaces, de trajetos múltiplos, e por sua natureza multidisciplinar, é uma arte de fronteira. Aparece sempre em sua dimensão de ação, na relação da ação do corpo em um espaço específico $\mathrm{Na} A r t$ Performance observa-se a associação dessa expressão à presença corporal direta do performer, ou seja, há uma interdependência entre corpo e performance Segundo Glusberg, trata-se do "uso do corpo como sujeito e força motriz" (2009, p.11), o corpo é o protagonista do processo performativo. A Performance também é marcada pela ideia do fenômeno não linear, pela presença do acaso e do imprevisível, particularidade, em grande medida, herdada das vanguardas artísticas, e mais recentemente, na música de John Cage e George Brecht, na pintura de Pollock, na arte do grupo Gutai e Fluxus. Em todas essas experiências defende-se a ideia de que não interessa o resultado, mas o processo, a ação, a duração. Há uma concepção inicial geradora de uma situação, mas essa situação está sujeita a imprevistos e indeterminações, que são solucionadas no meio do caminho.

Esse aspecto diz respeito ao desenvolvimento de uma sensibilidade háptica, no sentido de Bruno $(2007)^{8}$, que resgata a problemática do movimento e percepção háptica no projeto historiográfico e interartístico, para assim realizar um Atlas da Emoção ${ }^{9}$, ou seja, os conceitos propõem uma indivisibilidade perceptiva entre exterior e interior, que se conjugam na configuração de mapas mentais $A$ compreensão do fenômeno exige ora uma dimensão mais scinestésica (Noronha), ora mais espaciovisual (Bruno). Afirmando que a historiografia da história da arte tem uma dívida com a dimensão corporal, Bruno cunha o termo espacio-visual, correlacionando não apenas a pintura e o cinema, a fotografia e o cinema, mas também o design e o cinema,

\footnotetext{
8 A visão tátil tem por base uma reconsideração do háptico nos estudos das artes, arquitetura e design. A visão tátil é o que caracteriza a sensibilidade além da perspectiva ótica enunciada a partir do Renascimento. O termo foi proposto inicialmente pelo teórico da arte Alois Riegl e seu trabalho influenciou as teses de Walter Benjamin acerca da teoria da forma da arte cinemática. Por háptico entende-se neste a transição da perspectiva ótica para uma visão ampliada de uma emoção-movimento, espacial-temporal, na qual a visão (paradigma visual hegemônico na organização dos sentidos) é reintegrada no sentido de localização, numa inseparabilidade entre exterior e interior e na configuração de mapas mentais. Há uma ampliação dos sentidos enquanto modos de cognição e o estabelecimento de sensos topográficos e realidades topológicas.
} 
convocando a existência de uma rota háptica no espaço do design: a visão tátil. As rotas hápticas dizem respeito a um paradigma cinemático e suas afecções na produção artística. Essas considerações são importantes não só na compreensão do objeto, mas também nos processos e sistemas de produção, definindo novas posições do designer/artista, do teórico e do público. Assim se estabelece uma ampliação dos sentidos enquanto modos de cognição e de sensos topográficos e realidades topológicas

Partindo da observação do conceito de Performance Artística - principalmente dos fenômenos de processo, dinâmica e acaso - e comparando com o fenômeno do design contemporâneo (projeto e efetivação da obra), elaboramos quatro conceitos analíticos. São eles: Performance Conceitual, Performance Process, Techno Performance, Performance (In) Doors/(Out) Doors.

A Performance Conceitual trata de explorar a performance do autor (a ação de criação, o conceito do projeto, a postura do designer) como parte da compreensão do projeto e sua efetivação, no estudo da obra como autografia. A compreensão do objeto/ambiente e a escrita da memória também se dão através da performance criativa do designer. Sabendo que este, ao elaborar o projeto "fala" de um universo distinto, buscamos perceber sua metodologia, suas ambiguidades. Tentar apresentar o processo criativo implica a compreensão do designer e as mudanças que se operam em sua trajetória. Implica também apreender a opinião que ele tem do seu próprio trabalho, através do seu discurso teórico, observando-o no contexto História do Design, para então formular questões acerca do conceito da obra. A ideia é mostrar a interligação constante da retórica, poética e semiose na obra, já que todos estes elementos vivem em tensão. Aqui tratamos da memória do processo de criação e do resultado em projeto, que são particulares a cada autor ${ }^{10}$.

A Performance Process visa entender o trajeto de efetivação da obra, do projeto a sua realização - ou seja, a "memória construtiva". Quando se vê um ambiente, ou objeto finalizado, dificilmente se tem ideia da complexidade do trajeto percorrido. A fase da efetivação evidencia um percurso muitas vezes não-linear: é no canteiro de obras/na oficina que se confronta a fantasia do autor frente às demandas da realidade, no ato de efetivação aparecem desafios de toda ordem: nesse momento questionamos nossa tecnologia, a qualificação dos profissionais, a qualidade do material, a logística, os custos. É também no processo que o designer retifica o projeto, modifica detalhes, faz as últimas escolhas.

Na Performance Process o que se tem em vista é a memória que gira em torno do fenômeno finalizado. As relações objeto/ambiente $x$ performance são investigadas na efetivação do projeto e seu processo, surgindo daí a ideia do designer como narrador e o projeto como narrativa não-linear. A operação proposta é a de cruzar o

\footnotetext{
10 Importa ressaltar que o que se denomina em design Anteprojeto, com seus conceitos internos, se assemelha à mise en intrigue ricoeuriana. Mas diferentemante da narrativa literária, ao se tornar um projeto, torna a narrativa textual, tridimensional, desdobrando a mise en intrigue em diferentes planos. Ao ser detalhada, a obra opera outro desdobramento: um estudo representado graficamente em 04 pranchas, por exemplo, pode dar origem a uma multiplicidade de pranchas de detalhamentos. Isso é o que diferencia o design da literatura, e o que diferencia um designer do outro. Os "textos" visuais devem ser lidos tanto na ordem sequencial linear, como num livro (ocidental), como em uma ordem de sobreposições de planos, em "layers".
} 
espaço e o tempo através dos atos de executar e narrar: ao fundir a espacialidade do relato e a temporalidade do ato de efetivação/construção encontramos a dialética da memória e a obra em um mesmo núcleo de atividade.

Para pensar o design enquanto processo, acionamos parte do termo cunhado por Renato Cohen (2006) -"work in progress" - para pensar o "work in process" da "cena". Subvertendo o sentido clássico da narrativa, Cohen busca nos paradigmas contemporâneos da linguagem uma forma para teorizar a Performance, partindo da "estrutura" do hipertexto (caracterizado pela aleatoriedade e sincronicidade) que cogita o procedimento de criação cênica não como obra acabada, mas como obra em processo. O termo work in progress carrega a ideia tanto de trabalho e como de processo: como trabalho, acumulam-se duas noções, o da obra acabada, como produto, e o de obra em processo de feitura, em percurso. Como processo, implica interatividade, permeação e risco (risco de o processo não se fechar enquanto obra acabada) (Cohen, 2006, p. 20-21).

A obra de design, ao contrário de ser pensada em sua incompletude e a incompletude pensada como uma virtude - se pensa como obra acabada. O que se quer dizer com a absorção de parte do conceito de Cohen é que o processo é tomado também pelo acaso, por mais que uma obra seja planejada. Muito da produção da arte contemporânea que se produz hoje se torna acidente; muito da produção do design por mais que seja planejada como um todo, é também tomada pelo acaso, e ao final do processo, se efetiva em sua incompletude, deixando marcas pelo caminho. Muitas vezes as mudanças de trajeto implicam um desvirtuamento do projeto inicial. Nesse sentido, a obra efetivada incorpora as vicissitudes do caminho, os acasos das mudanças de rumo no decorrer da efetivação, o atravessamento de multiplicidades, produzindo "outra" cena no canteiro de obras ou na oficina, na qual o acidente ou as rachaduras configuram-se em realidades existenciais.

Assim, o designer e seus parceiros, ao se apropriarem do lugar ou das maquetes e mocapes, caem em "outro" terreno, ou seja, outras realidades surgem durante a obra: há uma coexistência do linear e do não-hierárquico no processo de concretização de qualquer projeto, ou seja, há uma ordem secreta do caos e do imprevisto dentro da ordem linear da concretização da obra. Além disso, ressaltamos que alguns processos criativos se efetivam com a "obra" em andamento; deste modo, as mudanças de rumo e adaptações fazem parte do processo construtivo.

A análise processual do planejamento e efetivação no campo do design se torna indispensável à sua compreensão, visto que neste âmbito se encontram várias realidades: a tecnologia proposta é confrontada com certa logística, a complexidade do projeto se defronta com a mão-de-obra local. É nesse momento que se analisa a performance dos profissionais, dos fornecedores, etc., e todas as tensões que decorrem do ato de construir/efetivar.

A Techno Performance é um conceito exploratório inter-relacionado, pois se liga a todos os outros conceitos: trata-se de relacionar o design com o ideia de dispositivos ${ }^{11}$ de Agamben (2009) e sua capacidade de "capturar, orientar, determinar,

11 Foucault (apud Agamben, 2009, p.28) propõe uma chave de leitura para o termo dispositivo: através de um procedimento filológico demonstra como oikos (termo grego utilizado na compreensão da gestão doméstica) se transforma no termo latino dispositio, e como este, por sua vez, ganha o significado de uma economia que regula o comportamento e se interioriza no sistema de crenças e sentimentos do 
interceptar, modelar, controlar e assegurar os gestos, as condutas, as opiniões e os discursos dos seres viventes" (Agamben, 2009, p. 42). Aqui tratamos especialmente dos dispositivos tecnológicos, que provocam uma mudança de orientação que se desvia do eterno para apreender o novo, ou seja, são as práticas que buscam os processos em desequilíbrio para engendrar uma emergência. Os dispositivos tecnológicos são capazes de modificar e capturar as condutas dos indivíduos sujeitos à sua convivência, abrindo as portas para múltiplos processos de subjetivação. Com o aumento dos dispositivos no mundo contemporâneo, pode-se inferir, em seguida, uma proliferação de subjetivações. No entanto, Agamben demonstra que pode acontecer exatamente o contrário, os dispositivos "não agem mais tanto pela produção de um sujeito quanto por meio de processos de dessubjetivação", ou seja, os dois processos, o da criação do dispositivo e a subjetivação estão cada vez mais dissociados da formação de um novo sujeito, a não ser de forma espectral, dependente e precária.

o design inteligente e complexo é muito apropriado na discussão contemporânea que investe nas dimensões tecnológicas. Não se pode deixar de refletir até que ponto a tecnologia opera uma relação de dominação e esvaziamento do sujeito, ou, por outro lado, o quanto o design pode transformar essa relação em uma dimensão libertadora.

Por último apresentamos a Performance (in) doors/(out) doors. Esse conceito levanta as intersecções entre narrativa (narratologia) e performance (performance art; performance e plot artístico-arquitetônico narrativo) entendidas aqui enquanto a provocação do objeto/espaço ao acontecimento do corpo, e por conseguinte, da criação de subjetividades. Trata-se de refletir sobre de que maneira a obra funciona como modo de afecção e provocação para o movimento, do design para o acontecimento: um design performático (performativo), um design pensada como ocasião para promover ações. O conceito adota o sentido dos mapas cognitivos e afetivos (Giuliana Bruno) e o sentido de comissuras (Kristine Stiles, 1998). É nesta fase que entra em ação o historiador-crítico, ao analisar a obra não só do ponto de vista do processo-projeto, mas principalmente do ponto de vista do háptico, aquele que estabelece uma relação de ação do corpo x corpo obra. É a partir desse conceito - e de sua proposta em analisar a obra em um processo de experimentação - que se analisa sua historicidade.

Alguns exemplos do design contemporâneo ilustram, de forma abrangente, o que Kristine Stiles (1998) denomina comissuras ${ }^{12}$ - conceito que sublinha a interligação e o comprometimento entre as ações performáticas, os objetos e sentidos que delas derivam, dramaturgia e performance que se constitui de justaposição ou encontro de

indivíduo. "... [dispositivo] implica discursos [...] leis, medidas administrativas [...] o dispositivo tem uma natureza essencialmente estratégica, que se trata, como consequência, de uma certa manipulação de relações de força, de uma intervenção racional e combinada das relações de força, seja para orientá-la em certa direção, seja para bloqueá-la [...]. Assim o dispositivo é: um conjunto de estratégias de relações de força que condicionam certos tipos de saber e por ele são condicionados" (Foucault apud Agamben, 2009, p. 28). Deste modo, dispositio corresponde à dialética entre liberdade e coerção, na relação entre os seres viventes (natureza) e os elementos históricos (dispositivo), entendendo como histórico o conjunto das instituições, dos processos de subjetivação e das regras em que se concretizam as relações de poder.

12 Kristine Stiles cria o conceito de comissuras (ponto de junção de duas ou diversas partes) para caracterizar os objetos que ficam como vestígios do ato performático. Para a autora, as imagens são como interfaces que possibilitam a reatualização da performance de forma infinita. 
partes, situações ou realidades. Pensando o conceito para o campo do design (e de um design cênico), comissuras significa a ação entre obra (e seus dispositivos) e interlocutor: o encontro entre o corpo da obra e corpo do usuário.

Nos processos de criação em design (e no design propriamente dito) há a valorização não apenas dos percursos e trajetos (movimento entendido numa perspectiva aristotélica), como também da dimensão de um espaço de fluxo e flutuações, onde o design é um interagente corpóreo que dinamiza e potencializa uma experiência narrativo-cênica. Partindo das correlações entre o conceito de performance e a teoria da Corporeal Narratology / Narrative Body refletimos como a obra pode se tornar uma superfície para a inscrição e para a provocação do movimento humano, convocando formas fluidas e poéticas deste mover-se, numa semiose muito particular. Como afirma Ryan (2004) o significado narrativo, e de uma dramaturgia cênica, é associado à capacidade de gerar constructos cognitivos e afectuais, mapas mentais e mapas dos afetos, "texturas" na pele da obra e na pele de seus interlocutores. A narrativa se constrói no confronto entre o usuário e a obra, e se dá em uma relação ativa do dispositivo. É no movimento que se realiza a significação, no contato com o cenário e com os objetos ${ }^{13}$.

Tal como afirma Noronha (2011-A) a narratologia "cênica" valoriza situações que são específicas da dança, de um parâmetro narrativo que não é só um fluxo de história, mas um fluxo do tempo e de uma não linearidade narrativa, ou seja, ele se instaura a partir de um padrão rizomático narrativo. O mapa produzido é adquirido pelo performer e depois compartilhado para universos de significação ampliados. Podemos afirmar que situação semelhante é a do visitante de uma obra de design de interiores, quando realiza uma performance, a partir do embate com dispositivos de natureza reativa ${ }^{14}$, ou melhor dizendo, a partir de um Script espacial, que deflagra múltiplas ações e reações.

Assim, sugerimos analisar o designs a partir da ideia de um texto-espaço que se destina a ser executado. Mas, de uma invariabilidade do roteiro básico, abre-se possibilidades: a variabilidade de sua execução. O design é projetado para uma construção cognitiva, mas a abordagem performática não se limita à reapresentação de eventos por um narrador; pode ser contada, mostrada e adotada como atividade auto-compensadora: as narrativas podem ser geradas dinamicamente durante a execução, através de movimentos/eventos. O objeto/espaço não conta uma história diferente para cada leitor-visitante, é este que reorganiza mentalmente a narrativa. A reconstrução de um mundo narrativo consiste em partir de um discurso codificado, fragmentado e entregue ao leitor/usuário/visitante como um puzzle, assim como um hipertexto. A originalidade está em explorar a obra e fazer, dessa experiência, uma

13 Analisando pelo lado da criação observa-se que a indicação para o movimento já está implícito no planejamento como na promenade arquitetural de Le Corbusier, por exemplo, das rampas helicoidais da Vila Savoye (1928-33). Isso fica mais evidente nos projetos de Bernard Tschumi, que se inspira na materialização do movimento, criando promenades cinemáticas, como no Parque de La Villete (198283), no qual a forma arquitetônica é planejada pensando no decurso dos eventos, ou seja, na ordenação tempo-espaço dos dispositivos arquitetônicos. A construção de uma narrativa, nesse caso, se dá no trajeto, na relação entre imagem e movimento.

${ }^{14}$ Ryan, teórica de mídias eletrônicas, define reativo quando se responde a mudanças no ambiente ou ações não intencionais do usuário. Interativo quando a entrada se origina em uma ação do usuário deliberada. Interatividade não significa necessariamente que o sistema irá agir da forma pretendida pelo utilizador. Aqui se fala do aspecto performático da narrativa (Ryan, 2004-A, p.30). 
narrativa. O leitor é levado - num contexto performático - a unir textos a partir de fragmentos heterogêneos, como um patchwork, alguns reciclados a partir de outros textos em uma atividade produtiva, criando ao final, histórias "naturalmente" topológicas.

O design, como forma do objeto/espaço e objeto interartístico e intermidial permite pensar na provocação entre o corpo da obra e o corpo 'da' e 'na' cena (do ambiente, edifício, terreno, da paisagem e da cidade) e as formas contemporâneas do corte e Intervalo, gerando desafios aos modos de se pensar o corpo e o movimento num jogo entre interior e exterior (INDOORS, OUTDOORS), surgindo daí novas visualidades, e formas oníricas e fantasmáticas. É deste "outro" lado do corpo da obra que se promove uma interioridade e uma espacialidade desdobrada, que se relaciona com o corpo do usuário, do visitante, do público, e convoca e potencializa uma experiência narrativo-cênica privilegiada. É do contexto narrativo que emergem temporalidades outras, e novos modos de ação: "em toda narrativa (especialmente, na contemporaneidade), há espaço para a aleatoridade, o padrão-rizoma, o caos (caosmose)" (Noronha, 2011-A, p.6).

A obra deflagra uma experiência scinestésica em que os estados do olhar são variáveis - como também sugere Giuliana Bruno (2007) -, onde se a instaura um mapa afectual, nos termos de design-textura, uma obra em (des-) montagem, um VISUAL TRAVELOGUE, um diálogo e uma viagem pelas cavidades do interior de um corpo. Nesse sentido, importa ressaltar que a análise da obra deflagra um tipo de percepção' que traça diversos planos:

“... deslocamentos corporais no espaço (do movimento aos trajetos), envolvendo ainda na tridimensionalidade (ou nos efeitos dela) o tato, o paladar, o olfato, a terceira dimensão, uma musculatura tátil e impressiva, combinando procedimentos, médiuns e códigos na constituição de linguagens híbridas / interartísticas, em amplas operações conceituais promotoras de um desafio à cultura, [...] um senso de experimentação que desorienta a navegação convencionada culturalmente, obrigando a cada um de nós [...] a reconquistar os seus sentidos". (Noronha, 2008-A, p. 6).

Essa perspectiva diz respeito ao desenvolvimento de uma sensibilidade háptica, que resgata a problemática do movimento no projeto historiográfico e interartístico, para assim realizar um Atlas da Emoção, ou seja, os conceitos propõem uma indivisibilidade perceptiva entre exterior e interior, que se conjugam na configuração de mapas mentais. Afirmando que a historiografia da história da arte tem uma dívida com a dimensão corporal, Bruno (2007) questiona o ocularcentrismo e convoca a visão tátil. Nesta mudança teórica do ótico para o háptico move-se da perspectiva do olhar fixo para o "olhar" em movimento. Ao contrário da pintura e escultura, que exigem um recolhimento necessário à sua fruição, o design contemporâneo exige uma experiência scinestésica. Deste modo, "sentir" a arte contemporânea é análogo à experiência de imersão no design: há uma percepção de forma mais abrangente, que inclui o corpo e as sensações como elementos privilegiados na relação.

Duarte e Noronha (2011) apontam que o PLOT cênico também possui uma significação geográfica, de um terreno cuja rede é passível de interpretação. Para a arte, o design e a dança cênica contemporâneas trata-se de pensar tal como 
propugnam os arquitetos Julien de Smedt e Bjark Ingels: numa prática artístico-estética se faz necessário tomar um princípio narrativo (uma teorização e suas práticas) e fazer delas uma série de acontecimentos envoltos em uma vasta trama (tensão e núcleos dramáticos esparsos, os diversos plots). Cada "espaço" se abre em múltiplos plots dramáticos, e neles faz-se do incidental, um modo constelacional, abrindo-se rumo aos passados e aos futuros. O desafio contemporâneo é o de como provocar modos narrativos (Ryan), e deles inferir formações aleatórias e elípticas que abrem e fazem fulgurar significações. Em todo contexto narrativo emergem temporalidades e modos de ação, de padrão rizomático. Ou seja, o narrador-historiador é um performer que "atua e recupera sua posição de fantasma", que narra na atualidade, mas sugere uma virtualidade.

Cumpre salientar que esse empreendimento exige conceitos que convoquem uma "nova ordem das coisas", ou seja, o fulgurar de uma nova "constelação". Em nossos estudos, especificamente, buscamos, entre, outros, dois elementos para provocar o aparecimento de múltiplos plots narrativos: a obra é atravessada pela desconstrução (Derrida) e pela dobra (Deleuze). Esses dois conceitos dão abertura para a emergência de diferentes modos de análise, interpretação e compreensão do design, uma vez que acionam nossa subjetividade. Do outro lado está a obra, com seus dispositivos - revelando o incidental.

A experiência estética afeta as formas da apreensão e cognição da realidade, os modos de ver e de "falar" de um território existencial. Tal experiência parte de um acontecimento de design que enuncia sensações, é uma provocação para a "escuta" da obra. Pensando o modo como o design influencia o comportamento humano, com a propriedade de criar sensações, percepções e desencadear afectos, a Performance (in) Doors/(out) Doors coloca o corpo no centro das atenções. Se algumas das finalidades do design são sua fruição e experiência estética, resultantes de sua apropriação, é necessário interpretá-las tanto por sua matéria como por sua linguagem poética, como uma narrativa espacial que personifica a temporalidade. A experiência scinestésica ${ }^{15}$, deste modo, torna o historiador partícipe da obra, complementando-a, reconfigurando-a. A capacidade da organização espacial/topológica em "sugerir" a conduta do visitante - através de seus dispositivos - contribui para a reestruturação das relações entre fruidor e obra (acionando novas experiências e criando novas subjetividades). Nesse sentido ressaltamos a dimensão pedagógica das práticas estéticas e suas estratégias espaciais/topológicas, que provocam reflexões sobre

\footnotetext{
${ }^{15}$ A Scinestesia pode ser ligada ao tema retórico (relacionada a doutrina do Ut pictura Poiesis) ou ao que se denomina hibridação conceitual - quando características semióticas são transportadas de um meio para outro. O termo aponta para uma conjunção entre Sinestesia e Cinestesia, e diz respeito à reintegração de duas condições no campo da pesquisa da linguagem: a primeira (sinestesia) é a relação de planos sensoriais diferentes, ou seja, a capacidade de tradução inter-percepções, num grau indicial (plano semiótico), estabelecendo relações entre uma percepção de um domínio do sentido e outro domínio evocado. O termo é usado para descrever uma figura de linguagem e uma série de fenômenos provocados por uma condição neurológica, no cruzamento de sentidos, em uma conjunção sensorial. Já Cinestesia tem um sentido de reintegrar a perspectiva do corpo na fruição da obra, pois o termo diz respeito à percepção dos movimentos, cuja natureza permite a realização de informações táteis, a propriocepção. Integrando os termos em um único, Noronha fortalece a perspectiva de que a "tela de projeção é sempre um lugar habitável, e o espaço construído sempre uma tela de projeção", ou seja, multiplica as perspectivas para uma teoria da percepção que passa a ser compreendida enquanto uma teoria da linguagem.
} 
formas do subjetivo que estão além do instituído - explorando a força de (re) invenção como fonte geradora de valor. $O$ design dá expressão às transformações nos modos de produção da atualidade, propondo sensibilidades cognitivas específicas, que demandam também performances capazes de transformar afecções em capital cultural.

\section{CONCLUSÃO}

Ao longo do tempo o designtem sido capaz de oferecer muito mais do que uma solução técnica para a necessidade pragmática: com seu próprio universo de discurso, seu significado se encontra além da epiderme da obra. Sua realidade é infinitamente complexa, fruto de sua relação com a história e a cultura. O reconhecimento de que a arché do design não é apenas uma equivalência semântica, ao contrário, ela ocorre na experiência, sugerimos sua assemelhança ao campo das artes da literárias: o significado de um romance é inseparável da experiência do próprio romance. Portanto, a circunscrição dos fundamentos epistemológicos da disciplina exige a compreensão do objeto ou ambiente de design enquanto experiência.

Dentre as abordagens encontradas para uma história do design numa interface com o campo do saber histórico mais vasto, identificamos que a análise hermenêutica - a hermenêutica interartística, de natureza transdisciplinar - se torna interessante à compreensão do objeto/ambiente. A partir da teoria da interpretação e da noção do design enquanto narrativa entramos na dimensão temporal da obra, enquanto projeto, construção e percurso. Buscando o sentido, a interpretação aplica o espírito sobre as formas, introduz nos signos valores que implicam o vivido e o existencial, ligados tanto ao mundo da obra quanto ao mundo do intérprete. Esse é o locus próprio da abordagem hermenêutica. O mundo que a obra documenta entrelaça vários elementos: o intérprete pronuncia o universo do autor e o contexto que envolve a obra. Mas ao esboçar sua interpretação da obra e do mundo por ela desvelado, acrescenta seu próprio mundo, tal como o designer acrescenta sua própria visão, ao interpretar o mundo e a si próprio no momento da criação. Só através desse entrelaçamento é que a obra passa a ser fonte de sentido e não apenas remetente de significados.

A compreensão responde à face subjetiva da interpretação, os novos sentidos adquiridos pela obra nas condições em que ela foi apropriada na história se colocam, no presente, ao intérprete. Para incluir tanto a compreensão quanto a explicação, este modo interpretativo faz dialogar permanentemente a parte e o todo, polos do círculo hermenêutico cujos sentidos só se manifestam quando referidos um ao outro: não se pode conhecer o todo sem se conhecer as partes, mas estas só são conhecidas em função do todo. Ao introduzir a compreensão ou o modo em que a obra é apropriada pelo intérprete situamo-nos no centro do círculo hermenêutico, que procura capturar o sentido do design, girando entre o autor, o fruidor, o intérprete e a obra.

Os conceitos de Performance surgem de nossas observações nos diversos campos da criação nos últimos anos. Temos como o objetivo principal analisar, interpretar, compreender e criticar o objeto de pesquisa, no sentido de alimentar tanto a pesquisa como a criação. Nosso desafio cumpre o papel imprescindível na teorização atual, por abrir um caminho - que não se pretende absoluto - na compreensão do fazer artístico contemporâneo e suas diversas formas de subjetivação. 


\section{REFERÊNCIAS}

AGAMBEN, Giorgio. O que é contemporâneo? E outros ensaios. Chapecó: Argos, 2009.

DUARTE, Valquíria G.; NORONHA, Márcio Pizarro. Performance e arquitetura: uma transmutação conceitual a partir do estudo do edifício da Fundação Iberê Camargo, de Álvaro Siza. In: Anais do II Congresso Internacional de História da UFG de Jataí. Jataí, 2011.

\section{INDOORS, OUTDOORS: Dança-teatro e} Arquitetura, Hibridações, Sincretismos e Performance a partir de Álvaro Siza (projeto e edificação da Fundação Iberê Camargo, Porto Alegre - RS). Anais III Seminário e Mostra Nacional de Dança Teatro de Viçosa, 2010.

BOIS, Y. (2007) A questão do pseudomorfismo: um desafio para a abordagem formalista (13-27). In: RIBEIRO, M. A. \& BRANCO, M. I. (orgs.). Anais do XXVI Colóquio do Comitê de História da Arte. Belo Horizonte: C/Arte.

BRUNO, G. Atlas of emotion: journeys in art, architecture, and film. New York: Verso, 2007.

COHEN, Renato.Work in progress na cena contemporânea: criação, encenação e recepção. São Paulo: Perspectiva, 2006.

Paulo: Perspectiva, 2009.

Performance como linguagem. 2o edição. São

DIDI-HUBERMANN, Georges Ante el tiempo. Historia del arte y anacronismo de las imágenes (FUNES, O. A. Trad.) Buenos Aires: Adriana Hidalgo, 2000.

FRIED, M. Arte e objetividade. (Machado, M. Trad.) (ano IX, n.9). In: Arte \& Ensaios, Revista do Programa de Pós-Graduação em Artes Visuais da EBAUFRJ. Rio de Janeiro: UFRJ, 2002.

GLUSBERG, Jorge. A arte da performance. São Paulo: Perspectiva, 2009.

KRAUSS, Rosalind E. La escultura em el campo expandido. La originalidad de la Vanguardia y otros mitos modernos. Madrid: Alianza, 1996.

MACHADO, I. Redescoberta do sensorium: rumos críticos das linguagens interagentes. In: MARTINS, M. H. (org.) Outras leituras: literatura, televisão, jornalismo de arte e cultura, linguagem interagente. São Paulo: Ed. Senac - Itaú Cultural, 2000.

MELENDI, M. A. Contra o formalismo (outra vez?). Disponível em: <http:// www. eba.ufmg.br/grupo/textoiti02.htm> Acesso em 30 jan, 2012.

NORONHA, M. P. A noção de composição no tratamento de sistemas Interartes: um estudo classificatório de experimentos sensoriais a partir da modernidade. In: Anais do IV Fórum de Pesquisa Científica em Arte da Escola de Música e Belas Artes do Paraná. Curitiba: UFPR, 2006

Interartes e Dança: uma pequena história entre o háptico e a scinestesia In: ENGRUPE - DANÇA - Encontro de grupos de pesquisa em dança. São Paulo: UNESP. 2007-A CD-ROM. 
Performance e audiovisual: conceito e experimento interartístico - intercultural para o estudo da história dos objetos artísticos na contemporaneidade. In: Anais do XXVI Colóquio do CBHA. São Paulo: FAAP. 2007-B.

Teoria Interartes: "Scinestesia", embodied experience [Performance? Body Art?], Paradigma Audio Visual e a arte no tempo recente. Manuscrito não publicado. 2008-A.

Arcaico, Moderno, Popular. Reflexões em torno da noção de arcaísmo e a cultura visual. Disponível em: <http://www.marciopizarro.wordpress.com> Acesso em 28 ago, 2008-B.

Reflexões teóricas em torno de interfaces: psicanálise e interartes e as relações tempo-espaço. Agenda e pesquisas em andamento. Disponível em: <http://www.marciopizarro.wordpress.com> Acesso em 23 ago 2008-C.

Sob o giro da arte na leitura sintomal. Objetos epistemológicos modernistas, recalque, crítica e morte na leitura historiográfica. Disponível em http://www.marciopizarro.wordpress.com. Acesso em 23 ago, 2008-C.

O Historiador e a "Scinestesia": conceito e experiência na História e Teoria Interartes. In: PESAVENTO, Sandra J. (org). Sensibilidade e sociabilidade: Perspectivas de Pesquisa. Goiânia: UCG. 2008-E.

PRAZ, Mario Mnemosyne: The Parallel Between Literature and the Visual Arts.Princeton University Press, 1975.

RYAN, Marie-Laure. Narrative across Media. The Languages of Storytelling. Lincoln and London: University of Nebraska Press, 2004.

- Multivariant Narratives. In: SCHREIBMAN, Susan; SIEMENS, Ray; UNSWORTH, John (ed.). A Companion of Digital Humanities. Oxford: $\quad$ Blackwell, 2004.2 Disponível http://www.digitalhumanities.org/companion/ V

STILES, Kristine. Uncorrupted joy: international art actions. In: SCHIMMEL, Paul. Out of actions: between performance and objects, 1949-1979. Los Angeles: MoCAThames and Hudson, 1998, pp. 227-329.

SOURIAU, É A correspondência das artes: elementos de estética comparada. (Pinto, M. C. Q. M. \& CUNHA, M. H. R. Trad.). São Paulo: Cultrix/Edusp. 1983. 